\title{
Mujer y sociedad: construyendo y reconstruyendo la imagen social de las académicas
}

Autores:

Cecilia Landman Navarro. Enfermera - Matrona. Doctora en Educación, Profesor Titular Escuela de Enfermería. Universidad de Valparaíso, Chile. E- Mail: cecilia.landman@uv.cl

Imaginando los pasos realizados por Florence Nightingale para posicionar a la enfermería como una profesión moderna y proactiva e instalando los principios que guiarían la disciplina desde años tan remotos -siglo XIX- y en una sociedad tan restrictiva como fue la época victoriana. Su genuina rebelión se orientó no sólo contra los prejui cios de la época, sino que, contra el destino de las̄ mujeres, sin posibilidades de educarse ni salir del hogar para participar en los acontecimientos sociales (1).

Hoy más que nunca debemos reflexionar respecto a este largo caminar como mujeres y enfermeras, resignificar el sentido de nuestro quehacer, descubrir hacia dónde y cómo avanzamos para lograr una real igualdad, para hacer efectivo nuestro empoderamiento y reconocimiento en la sociedad (2).

Considerando que la enfermería ha sido una disciplina eminentemente femenina, situación que predetermina la ruta a seguir, dificultando alcanzar las metas trazadas por la dificultad de superar los roles sociales sexistas (3). Esta reflexión pretende identificar algunos de los factores que nos circundan como mujeres. Para el análisis, la perspectiva asumida no será desde el feminismo radical, sino que, desde el ejercicio del feminismo, como una necesidad de participación y de reconocimiento de igualdad en todos los planos sociales.

El camino reflexivo realizado es desde una mirada fenomenológica, de lo que significa la construcción y reconstrucción de nuestra imagen social, como mujeres y enfermeras ejerciendo distintos roles familiares, sociales y laborales.

\section{Género y construcción Social}

Para dar inicio a la discusión, Bárbara Caine y Glenda Sluga, profesoras de historia europea, en el texto "Mujeres en el cambio socio-cultural europeo 1780-1920, señalan que ha existido una falta de reconocimiento del género como categoría histórica. Los historiadores han privilegiado el rol masculino, atribuyéndole al hombre el ámbito de lo público, la actividad económica y 
y laboral. Y a la mujer la esfera privada, doméstica y familiar. Desde esta mirada eminentemente masculina, a las mujeres nos ha sido dificil transitar a un pleno reconocimiento social, para poder instalarnos en las áreas que se les ha asignado tradicionalmente, a los hombres, marginándonos como protagonistas sociales relevantes (4) e "integrar el sentido de ser parte de..." *.

El peso de los relatos masculinos, en este tránsito "de ser parte de..." la historiadora chilena Ana María Stuven, coincide con las autoras antes mencionadas respecto a la limitación existente en cuanto a la incorporación social y política de las mujeres, agregando que recién en los años 60s, el feminismo instala la discusión social del concepto de discriminación de la mujer en la historia. Esta historia como ya se ha mencionado antes ha sido relatada por hombres, lo cual le resta visibilidad al rol de la mujer, más allá de los roles tradicionales (5). Además, menciona una falta de reconocimiento académico de estudios de la mujer. Solo en los países anglosajones llevan un cuarto de siglo de desarrollo en esta área, sin embargo, apenas se enfatiza la presencia y contribución de la mujer al mundo real. La mujer se asocia principalmente a la esfera privada y menos a lo público, no como protagonistas, sólo se les reconoce valor y visibilidad a quienes ejercieron el poder y heredaron coronas (5).

En varios países latinoamericanos, incluido Chile, se crearon tempranamente -en la década del 70centros de estudios de la mujer, sin embargo, solo a finales del siglo pasado, se pudo trascender la separación rígida entre un espacio femenino y otro masculino, el primero radicado en el hogar y el segundo en lo público (5).

Es importante enfatizar, que actualmente, estamos viviendo un cambio cultural, que, aunque ha llegado tarde, se observa un creciente reconocimiento de la participación e influencia de las mujeres en los procesos sociales, culturales, económicos y políticos, fundamentales en la formación de los estados y en el desarrollo de la ciudadanía. Dando un sentido a la participación de las mujeres, como "de ser parte de...". Esta situación continúa siendo una historia inconclusa.

Junto con la invisibilidad histórica de la mujer, existe la violencia simbólica, que agrega otro elemento a la marginación o a permanecer en un plano secundario en la sociedad. El ejercicio de violencia simbólica se manifiesta a través del lenguaje sexista y de imágenes de mujeres-enfermeras con representaciones erotizadas, objetivándolas e irrespetando su rol profesional. Imágenes que se muestran en variados medios audiovisuales, que por su amplia difusión persiten en el imaginario cultural colectivo sexista del rol femenino.

Simone de Beauvoir, en el ensayo "El Segundo Sexo" ha dicho "...No se nace mujer: llega una a serlo", premisa que indica que la conceptualización de la mujer es un producto cultural, los atributos femeninos no son sólo biológicos, sino que son producto de una construcción social. A la mujer siempre se la ha definido en relación a un otro, como madre, esposa, hija, hermana, abuela, etc. De ahí que ella deba reconquistar terreno e ir al encuentro de su propio destino e identidad (6).

\section{Elgénero más allá de lasideologías}

En este largo transitar para ir al encuentro de la propia identidad, el feminismo se instala tanto, en la ideología liberal como en la socialista, muchas veces rotuladas en un discurso anti masculino y contra la familia, lo cual genera una barrera académica de desvalorización.

La controversia se produce por la imagen desdibujada que las personas le asignan al concepto de feminismo o ser feminista, muchas veces percibidas a través de la difusión de los medios. Karen 
Offen propone re-conceptualizar el término feminismo, de una manera más dinámica y flexible, alejándolo del dogmatismo y de las "etiquetas" como una manera de acercarlo a la comprensión pública. El feminismo como una ideología crítica, que se desarrolla y contextualiza en la realidad individual y relacional, rompiendo las barreras políticas e intelectuales centradas en el hombre, en ideologías religiosas y seculares occidentales, cristianas, protestantes, judaicas, liberales, socialistas o marxistas. El feminismo entendido como constructo socio histórico, que plantea problemas que conciernen a la vida personal, la autonomía o la la libertad, al debate entre la distribución históricamente injusta de la política, la participación social y el poder económico entre los sexos (7).

La interrogante ¿Quién decide por mí?, se convierte en la eterna discusión de definir lo que es lo mejor para las mujeres, sin consultarles, lo que perpetúa un sistema de patriarcado decisional. Sin embargo, Karen Offen no promueve un discurso anti-hombres, sino que pro-mujer, busca encontrar un reequilibrio en lo social, económico y político dentro de la sociedad, de ambos sexos, en nombre de su humanidad común, con respeto de sus diferencias, es decir, un feminismo transformacional (7). Rompiendo la barrera de lo que señala Beauvoir: "el problema de la mujer siempre ha sido un problema de hombres" (6).

\section{La mujery el trabajo}

El enfoque de género nos muestra otro problema, el abordaje de la división del trabajo entre sexos, donde existen diferencias significativas entre ambos, en cuanto a su comportamiento frente a la incorporación de la mujer al trabajo y al proceso productivo, desigualdades generadas por la persistencia de una ideología patriarcal, la cual genera confusas prácticas sociales, guiadas por el poder y la sumisión al padre, al jefe, a instituciones lideradas fundamentalmente por hombres. Nuevamente se produce la definición de ser mujer por un otro.

Un reciente estudio de la Organización Internacional del Trabajo, "Mujeres y trabajo 2016" muestra una brecha de género en la distribución de labores de cuidado, las tareas domésticas no remuneradas y el trabajo remunerado. Tanto en los países de economías en desarrollo, como en los desarrollados, las mujeres trabajan menos horas en un empleo remunerado y continúan asumiendo la gran mayoría de las tareas domésticas no remuneradas. Estas diferencias han ido disminuyendo con el tiempo, en el orden de una menor dedicación a tareas domésticas, pero no disminuyen las derivadas del cuidado de los hijos. En conclusión, hoy en día las mujeres tienen jornadas de trabajo en promedio más largas que los hombres, pero las más extensas responden al trabajo no remunerado, dejándola en condiciones laborales más precarias que al hombre (8).

Las diferencias salariales que lo anterior ocasiona, no se explicaría en términos de diferencias de edad o de nivel educacional, sino que más bien están vinculadas con la infravaloración del trabajo que realizan las mujeres, con prácticas de discriminación y con la necesidad de postergación de las carreras de las mujeres para asumir tareas derivadas del cuidado de los hijos y padres. El estudio de la OIT señala que, si prevalecen las tendencias actuales a nivel mundial, para eliminar la brecha salarial a igual trabajo, entre hombres y mujeres, se necesitarían más de 70 años, siempre y cuando los países adopten políticas de distribución equitativa entre hombres y mujeres (8).

La brecha de género en el trabajo, tiene repercusiones durante el periodo reproductivo de las mujeres, quienes deben pagar mayores primas en salud. En el largo plazo nuevas brechas en las pensiones de retiro, quedando demostrado que las mujeres perciben pensiones contributivas en 
un $10,6 \%$ inferiores a los hombres (8).

\section{Mujeres y universidad}

Las mujeres al abrirse al espacio de formación académica seleccionan carreras profesionales asociadas a las humanidades, la educación y la salud, con especial énfasis en la enfermería, entre otras. A las jóvenes se les ha inducido a elegir profesiones asociadas con los roles típicos del cuidado de los demás y la conservación de la familia, como tránsito natural desde el ámbito social-privado a lo social-público. La problemática de la mujer en la universidad ha sido abordada principalmente por el mundo académico anglosajón. En las universidades norteamericanas durante los 70s se tomaron medidas antidiscriminatorias para las mujeres y grupos étnicos al interior de la academia, por la doble discriminación sexo y etnia. Los estudios analizaban diversas formas de desigualdad, tales como contratos temporales, de tiempo parcial, criterios de contratación discriminatorios, salarios más bajos a una misma responsabilidad, menor reconocimiento, falta de seguridad laboral, contratos a plazo fijo, menos beneficios, entre otros $(9,10)$.

Las acciones que han desarrollado las universidades norteamericanas para atenuar las desigualdades van en el orden de publicación de manuales de comportamiento en el aula, ejercicios para sensibilizar a los compañeros de trabajo, terapias de apoyo para disminuir el stress, talleres, etc. Todas medidas que no resuelven efectivamente el problema $(9,10)$.

Otra brecha que existe entre hombres y mujeres ocurre en las trayectorias académicas, ocasionada por una menor presencia de mujeres en los ámbitos de las ciencias exactas donde se genera una mayor productividad científica. Los hombres quienes publican más artículos, reciben reducciones en sus cargas docentes para hacer investigaciones y logran mayores financiamientos, mientras que sus colegas femeninas realizan fundamentalmente seminarios en los que hacen usos de sus habilidades comunicativas, pero que tienen menores incentivos o reconocimientos. Además, las mujeres no disponen del tiempo para continuar con el trabajo en sus hogares, o ampliar el tiempo en los laboratorios, lo que también limita la posibilidad de investigar, a pesar de estar motivadas para ello. Si bien es cierto, se han estado generando espacios de cooperación de redes familiares, para afrontar esta situación, pero aún resta camino por recorrer, ya que aún persiste la tendencia entre los académicos "de llevarse trabajo para la casa", esto por supuesto afecta más la limitación de tiempo de las mujeres, considerando la disponibilidad para el cuidado familiar. El principal antecedente que promueve la mantención de esta desigualdad, es la asociación del rol de la mujer al ámbito doméstico y a la familia $(11,12)$.

Otro aspecto estudiado es la vivencia de la maternidad y matrimonio, las académicas posponen ambas situaciones, dado que estos tensionan al mundo académico, dificultando la realización de postgrados, especialmente en el extranjero, así como para asistir a eventos científicos. Se reconoce una tensión entre lo laboral y familiar, donde los roles y tiempos se comportan como elementos antagónicos, cuesta conciliar vida, estructura familiar y trayectoria académica $(9,12)$.

Profundizando más aún en este problema, Bourdieu, en su libro "Homo Academicus", menciona la existencia de una competencia constante entre académicos por el poder. Este poder, descansa en la posesión de un capital cultural, el cual no puede ser acumulado y mantenido, sino al precio de un gasto constante e importante de tiempo, del cual las mujeres disponen en menor cantidad que los hombres (13). 


\section{La brecha en la gobernanza}

Se reconoce la existencia del techo de cristal, se refieren a las barreras tanto internas como externas, en el acceso a cargos de dirección para las mujeres, denominado de cristal porque permite ver como alcanzables dichos cargos, no obstante, existe el impedimento de llegar a ellos. Las primeras barreras están constituidas por las conductas y actitudes femeninas, como el miedo a defraudar las expectativas sobre el papel femenino, falta de modelos femeninos de referencia, hacerse aceptar sacrificando la propia identidad. Siendo las externas, las propias de la estructura social y las creencias sobre el liderazgo y género (14).

Las revisiones realizadas dan como explicaciones a este fenómeno, al modelo de mando masculino tecnicista, que enfatiza valores del estereotipo de hombre, su capacidad de análisis, su dureza, incluso su fuerza física como indicativo de la capacidad de controlar. Todos estos atributos no corresponden con aquellos en los cuales hemos sido socializadas. Las mujeres académicas universitarias no estamos ajenas a la problemática que se les presenta a las mujeres trabajadoras en otros contextos laborales, compensar el sentimiento de culpa por dejar a su prole fuera del control maternal, el postergar su formación avanzada, en general, compatibilizar la actividad académica y la personal, al interior de una institución con una marcada tendencia patriarcal.

A pesar de los avances en cuanto a alcanzar mayores niveles educacionales por parte de las mujeres, se necesita de medidas transformadoras que permita la eliminación de la discriminación y la consecución de la igualdad de género tanto en el hogar, como en el trabajo, así lo sugiere la Agenda 2030 para el Desarrollo Sostenible, como propuesta de la OIT para el segundo centenario, en el año 2019 (15).
La tarea para la discusión es como incorporar una perspectiva femenina al interior de nuestras universidades. Esperando que esta reflexión sea una invitación a romper el techo de cristal y avanzar...

\section{Referencias Bibliográficas}

1. Young $P$, Hortis de Smith V, Chambi MC, Finn BC. Florence Nightingale (1820-1910), a 101 años de su fallecimiento. Rev médica de Chile. 2011; 139(6): 807-13.

2. Núñez R. Comprensión de la enfermería desde la perspectiva histórica de Florencia Nightingale. Cienc enferm. 2011; 17(1):11-8.

3. García AM, Sainz A, Botella M. La enfermería vista desde el género. Index Enferm. 2004; 13(46): 45-8.

4. Caine B, Sluga G. Mujeres en el cambio sociocultural europeo 1780-1920. Madrid (España): Narcea DL. 2000. 428 p.

5. Stuven AM. La mujer ayer y hoy: un recorrido de incorporación social y política. Centro de Políticas públicas UC: Instituto de Historia. 2013; 8 (61): $20 \mathrm{p}$.

6. De Beauvoir S. El Segundo Sexo. Editorial Sudamericana SA. 2002. 417p.

7. Offen K. Defining feminism: A comparative historical approach. Signs. Journal of Women in Culture and Society. 1988; 14(1):119-57.

8. Oficina Internacional del Trabajo. Las mujeres en el trabajo: Tendencias de 2016. Ginebra; 2016.

9. Ortiz F. Vida familiar y trayectorias 
académicas: una aproximación biográfica en una universidad chilena. Polis (Santiago). [en línea] 2017. [acceso 20 may 2018]; 16(47): 257-79. Disponible en: http://dx.doi.org/10.4067/S0718-65682017000200257

10. Gaete-Quezda R. El techo de cristal en las universidades estatales chilenas. Un análisis exploratorio. Rev iberoamericana de educación superior. [en línea] 2015[acceso 20 may 2018]; 6(17): 3-20. Disponible en: https://doi.org/10.1016/j.rides.2015.06.001

11. Martínez S. Ser o no ser: tensión entre familia, subjetividad femenina y trabajo académico en Chile: Un análisis de desde la psicología feminista. La ventana. Revista de estudios de género. 2012; 4 (35):133-63.

12. Martínez-Covarrubias S. Mujeres y Universidad. Colima (México): Universidad de Colima. 2006. 425 p.

13. Bourdieu P. Homo Academicus. Madrid (España): Siglo XXI; 2008. 320 p.

14. Tomás M, Guillamón C. Las barreras y los obstáculos en el acceso de las profesoras universitarias a los cargos de gestión académica. Rev de educación (Madrid). 2009; (350): 253-75.

15. Programa de las Naciones Unidas para el Desarrollo. Desarrollo humano en Chile. Género: los desafios de la igualdad, Santiago de Chile; 2010. 